https://doi.org/10.11646/zootaxa.4242.2.5

http://zoobank.org/urn:lsid:zoobank.org:pub:EB797A4E-5182-495C-BF94-FEC332BCCC90

\title{
New taxa of Orthoptera (Insecta Tettigoniidae Phaneropterinae) from Madagascar
}

\author{
BRUNO MASSA \\ Department of Agriculture and Forest Sciences, University of Palermo, Viale Scienze Bd 5A, 90128 Palermo, Italy. \\ E-mail: bruno.massa@unipa.it
}

\begin{abstract}
The author reports the results of a study on Orthoptera collected in Madagascar and preserved in two European Natural History museums. He describes Symmetroraggea depravata n. sp., Parapyrrhicia longipodex n. sp., Madagascarantia bartolozzii n. gen. n. sp., Mimoscudderia spinicercata $\mathbf{n}$. sp. In addition, he lists new records or unknown taxonomical characters of Xenodus nobilis Carl, 1914 and Parapyrrhicia virilis Carl, 1914.
\end{abstract}

Key words: taxonomy, new genus, new species, tropical Africa

\section{Introduction}

Natural History museums take care of huge numbers of specimens collected during zoological expeditions to unexplored and remote lands; only a small portion of this material has been studied, much work is still waiting. The present knowledge of taxonomical diversity of some orders or families of insects is still insufficient, particularly in some countries, like Madagascar, characterized by a very old isolation (Briggs 2003). Madagascar is a land where a high number of endemic species of grasshoppers and katydids live (Cigliano et al. 2016); even if researches and collections have been carried out since 1800, much work is still required to have a sufficient knowledge both in taxonomical and distributional terms. Everyone who has the chance to visit Natural History museums to study insects is surprised by the rich number of unidentified specimens, probably undescribed taxa. The present paper reports some little known or new taxa of specimens preserved in two European museums, the National Museum of Natural History of Prague (NMHP) and the Museum of Zoology of the University of Florence (MZUF); results show the importance of public collections there preserved, the scarce level of knowledge of some systematic groups and the scientific potential to investigate the different and numerous tesserae of the biodiversity mosaic.

\section{Material and methods}

Specimens were photographed with a Nikon Coolpix 4500 digital camera, mounted on a Wild M5 Stereomicroscope, and photos were integrated using the freeware CombineZP (Hadley 2008). Mounted specimens were measured with a digital calliper (precision $0.01 \mathrm{~mm}$ ); the following measures were taken (all measurements in $\mathrm{mm}$ ): Body length: dorsal length from the head to the apex of the abdomen, ovipositor excluded in females; Ovipositor: maximum length; the curvature of the ovipositor is not considered, the measurements were taken from the subgenital plate to the tip of the ovipositor; Pronotum length: length of the pronotum along dorsal median line; Hind femur: length of hind femur; Tegmina: length and maximum width of tegmina. 


\section{Results}

Fam. Phaneropterinae Burmeister, 1838

Tribe Phaneropterini Burmeister, 1838

\section{Gen. Xenodus Carl, 1914}

The Madagascan genus Xenodoxus has not been still reported within any tribe. However, its characters, a bit related to the genus Dioncomena Brunner von Wattenwyl, 1878, consent to place it within the tribe Phaneropterini.

\section{Xenodoxus nobilis Carl, 1914}

(Figs 1A-1H)

Material examined. Madagascar, surroundings of Rogez $\left(1 \delta^{\lambda}\right)$; Madagascar, Ampanefena $(1 \overbrace{}^{\lambda})$; Madagascar, Vahémar (10ิ, 2ᄋ) (NHMP).

Remarks. These are the first records after the description of Xenodoxus nobilis from Madagascar. Below peculiar characters of the species are reported.

Characters. Tegmina bicolored, anteriorly cream, posteriorly brown, hind wings dark, hind legs with black and white stripes (Figs 1A, 1B, 1H). Fastigium of vertex very narrow, eyes round, prominent, fronto-genal keels absent (Fig. 1G). Antennae very long, exceeding ca. $3 \mathrm{~cm}$ extended hind legs. Stridulatory file with big teeth in the distal part and smaller and evenly spaced teeth in proximal part (Fig. 1C); in the right tegmina only 11-12 teeth behind the speculum. Fore coxae armed, fore femora unarmed, fore tibiae with open tympana on both sides, superiorly furrowed, with 4 inner and outer ventral spines +1 spur on each side, 2 inner dorsal +1 spur; mid femora unarmed, mid tibiae with 6 inner and 9 outer ventral spines +1 spur on each side, 1 inner dorsal +1 spur. Genicular lobes with a pair of small spines. Last tergite ending with two lateral hook-like up-curved and pointed appendixes, apically crossing (Figs 1A, 1D). Cerci in-curved, stout at their base, then more slender, up-curved and pointed. Male subgenital plate narrow and long, with a deep concavity, its apices divergent and pointed (Fig. 1D). Ovipositor long and laterally flat, superiorly and inferiorly denticulate in the apical part (Fig. 1B). Female subgenital plate rhomboidal (Fig. 1F).

Measurements. Males. Body length: 12.3-15.0; length of pronotum: 2.6-2.9; length of tegmina: 19.0-21.3; width of tegmina: 3.2-4.0; length of hind femora: 16.1-17.5. Females. Body length: 14.4-15.6; length of pronotum: 2.7-2.8; length of tegmina: 19.0-20.0; width of tegmina: 2.8-3.2; length of hind femora: 16.5-18.0; ovipositor: $7.5-7.8$.

\section{Symmetroraggea depravata new species}

(Figs 2A-2E)

Material examined and depository. Holotype $\widehat{\delta}$. Madagascar, Ambanja (NMHP).

Description. Eyes oval, face without fronto-genal carinae; fastigium of vertex narrower than first antennal segment, sulcate above, not contiguous with fastigium of frons. Pronotum flat, with sharp margins (Fig. 2A). Tegmina narrow, with posterior margin nearly straight, blackish longitudinal line bordering the stridulatory area and extending posteriorly on left tegmen (Fig. 2A). Stridulatory file $1.4 \mathrm{~mm}$ long and constituted of ca. 50 evenly spaced teeth (Fig. 2E). Coxae armed, open tympana on both sides of fore tibiae; 5 spines on ventral margin of fore femora, 5 inner and outer spines +1 spur on each side of ventral margins of fore tibiae, fore tibiae dorsally rounded, not furrowed; mid femora with 8 outer spines, mid tibiae with 11 outer spines +1 spur and 6 inner spines +1 spur ventrally, 3 spines +1 spur dorsally; hind femora with 9 outer and 3 inner spines, hind tibiae with 14 outer and 12 inner dorsal spines +3 spurs on each side. Genicular lobes of hind femora provided with a pair of small spines on each side. Male last tergite posteriorly protruding and laterally divergent into two lobes, with central part concave and hind margin flat, supra-anal plate modified as one stout inflated extrusion, similarly shaped like the last tergite, and concealed below it; cerci stout, long, incurved, the apical part folded at obtuse angle, with a bulge on the fold 
and a bifid wide apex (Figs 2B, 2C); male subgenital plate exceeding cerci, short, wide, trapezoidal, posteriorly narrowed, with deeply concave apex; styli present but very small (Fig. 2D).

Diagnosis. Very characteristic and easily separable from $S$. dirempta Karsch, 1889 by its male genitalia.

Etymology. From Latin, depravatus = depraved, by its complicated male genitalia.

Measurements. Male. Body length: 18.9; pronotum length: 4.0; length of tegmina: 26.3; width of tegmina: 5.4; length of hind femora: 15.5 .

Remarks. The African representatives of the genus Symmetropleura Brunner von Wattenwyl, 1878 have been placed into two genera, Symmetrokarschia and Symmetroraggea (Massa 2015). The latter is known only from Madagascar and is characterized by the round margin of upper margin of fore tibiae and the fronto-genal carinae. Only one species, $S$. dirempta, was hitherto known. $S$. depravata $\mathbf{n}$. sp. presents similar fore tibiae, but not frontogenal carinae; however, it is here tentatively included within the genus Symmetroraggea. Its genitalia are very characteristic.

\section{Gen. Parapyrrhicia Brunner von Wattenwyl, 1891}

Actually 11 species belong to the genus Parapyrrhicia. Seven of them live in East Africa and have been revised by Hemp et al. (2016), three species are known from Madagascar, P. dentipes Saussure, 1899, P. madagassus (Karsch, 1889), P. virilis Carl, 1914; further, P. insularis Chopard, 1958 has been described from Comores Is. (between Madagascar and Africa).

Some new interesting records and morphological remarks on Madagascar species are below reported, together the description of a twelfth species, also from Madagascar.

\section{Parapyrrhicia virilis Carl, 1914}

(Figs 3A-3D, 4A, 4C, 4F, 4G)

Material examined. Madagascar, Ampanefena (1§); Madagascar, Vohémar (1 1 ) (NHMP).

Characters. Only the male of $P$. virilis was shortly described and later this species has no more reported; for this reason peculiar characters of both sexes are here listed.

Male (Figs 3A, 4A, 4C, 4F, 4G). Green with a two small blackish areas at the base of tegmina and along their hind margin. Eyes round prominent. Pronotum longer than high, anterior margin straight, posterior rounded (Fig. 4A). Stridulatory file curved and constituted of ca. 100 evenly spaced teeth (Fig. 3A). Fore coxae armed, fore femora with 7 small spines ventrally, fore tibiae with open tympana on both sides, superiorly rounded (not forrowed), with 5 inner and outer ventral spines +1 spur on each side; mid femora with 4 ventral outer spines, mid tibiae with 9 inner and outer ventral spines +1 spur on each side; hind femora with 3 inner and 12 outer ventral spines, hind tibiae with many spines +3 spurs on each side. All genicular lobes with a pair of small spines on each side. Last tergite long, pointed and down-curved (Fig. 4C). Cerci slender, long and incurved, flattened in the apical part (Fig. 4F). Subgenital plate narrow, ending with a wide concavity and two sulcate divergent lobes (Fig. 4G).

Female (Figs 3B, 3C, 3D). Same characters and colour of the male, with the following differences. Hind femora with 3 inner and 13 outer ventral spines. Ovipositor 2 times longer than pronotum, with upper and lower apices serrate (Fig. 3D). Subgenital plate small and triangular (Fig. 3B) [different from that of $P$. dentipes Saussure, 1899 and P. madagassus (Karsch, 1889)]. In addition, the female has on inner margin and on the dorsal area of right tegmen some transverse and longitudinal veins with little teeth covered by very small bristles (Fig. 3C), that certainly are used for acoustical communication with the male. A similar character (one to three transverse veins) has been already highlighted by Hemp et al. (2016) in the female of P. abdita Hemp, 2016. However, most females of Phaneropterinae have some teeth on the right tegmen to communicate with the other sex (Heller et al. 2015).

Measurements. Male. Body length: 23.0; length of pronotum: 4.8; height of pronotum 3.4; length of tegmina: 30.7; width of tegmina: 5.7; length of hind femora: 19.2. Female. Body length: 19.2; length of pronotum: 4.2; height of pronotum 3.1; length of tegmina: 31.5 ; width of tegmina: 5.9 ; length of hind femora: 19.0 ; ovipositor: 9.1 . 

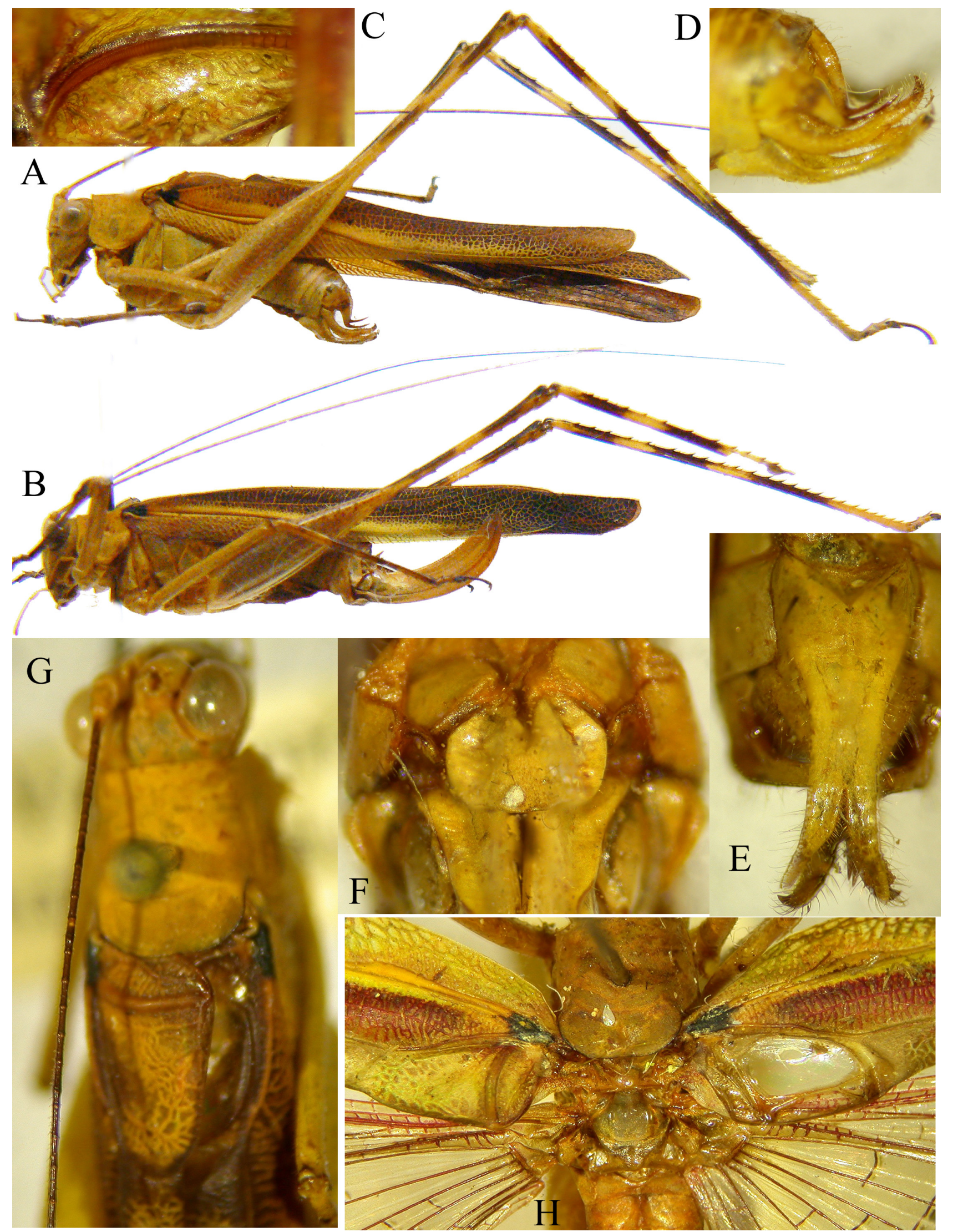

FIGURE 1. Xenodoxus nobilis, male: habitus (A), stridulatory file (C), lateral view of last abdominal segments (D), subgenital plate $(E)$, dorsal view of head, pronotum and stridulatory area $(G)$, stridulatory area of left and right tegmina $(\mathrm{H})$; female: lateral view (B), subgenital plate (F). 


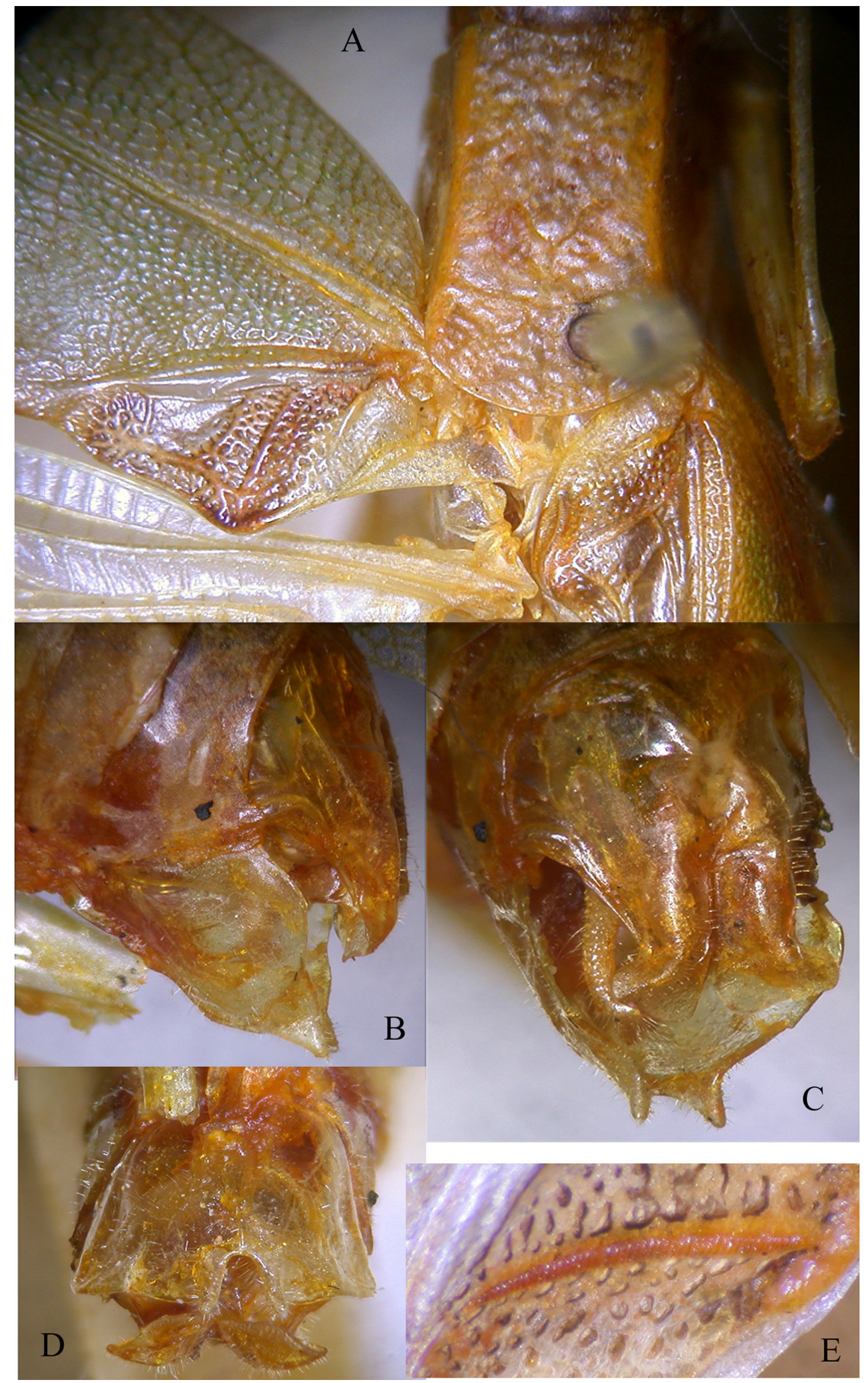

FIGURE 2. Symmetroraggea depravata n. sp., male: dorsal view of pronotum and stridulatory area of tegmina (A), lateral view (B) and dorsal view (C) of last abdominal segments, subgenital plate (D), stridulatory file (E). 

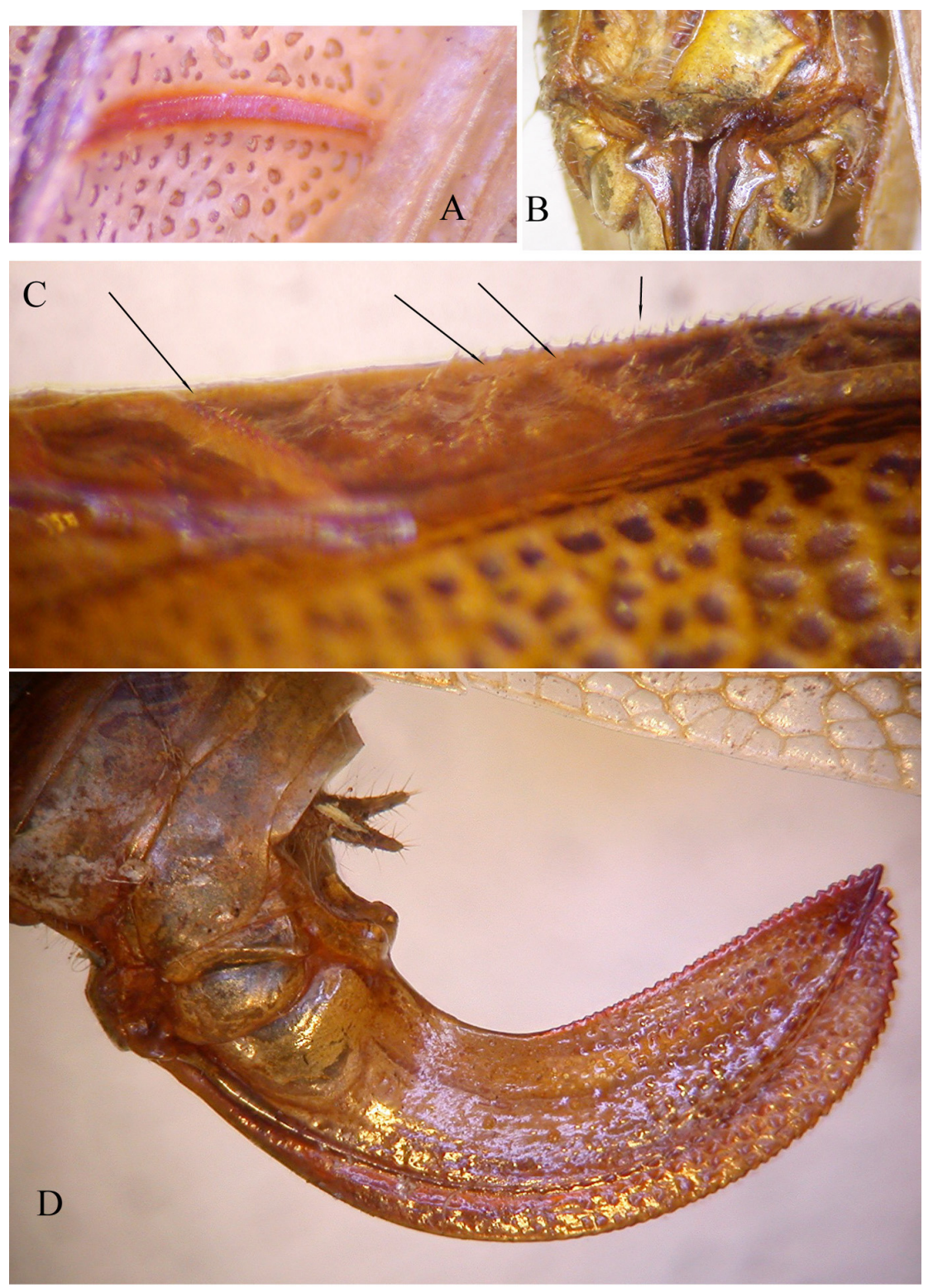

FIGURE 3. Parapyrrhicia virilis, male stridulatory file (A), female subgenital plate (B), stridulatory files on the right tegmen of female (C), lateral view of the ovipositor (D).

\section{Parapyrrhicia longipodex new species}

(Figs 4B, 4D, 4E, 4H)

Material examined. Holotype $\widehat{\delta}$. Madagascar, Ambanja (NHMP).

Description. Male (Figs 4B, 4D, 4E, 4H). Green with a small blackish spot on the stridulatory area. Fastigium of vertex very narrow, just furrowed, not distinct from fastigium of frons, eyes round oval, prominent, fronto-genal keels absent. Antennae incomplete in the holotype. Pronotum longer than high (Fig. 4B), anterior margin straight, posterior rounded. Fore coxae armed with a small spine, fore femora with 4 small spines ventrally, fore tibiae with open tympana on both sides, superiorly rounded, with 5 inner and outer ventral spines +1 spur on each side; mid femora with 3 ventral outer spines, mid tibiae with 13 inner and outer ventral spines +1 spur on each side, 3 inner dorsal +1 spur; hind femora with 9 inner and outer ventral spines, hind tibiae with many spines +3 spurs on each side. All genicular lobes with a pair of small spines on each side. Last tergite very long, pointed and down-curved; supra-anal plate hidden below the last tergite (Figs 4D, 4H). Cerci stout, incurved, shorter than the last tergite, with a black chitinous inner not pointed spine before the apex (Fig. 4E). Subgenital plate very long and narrow, divided into two apically convergent lobes (Fig. 4H). 


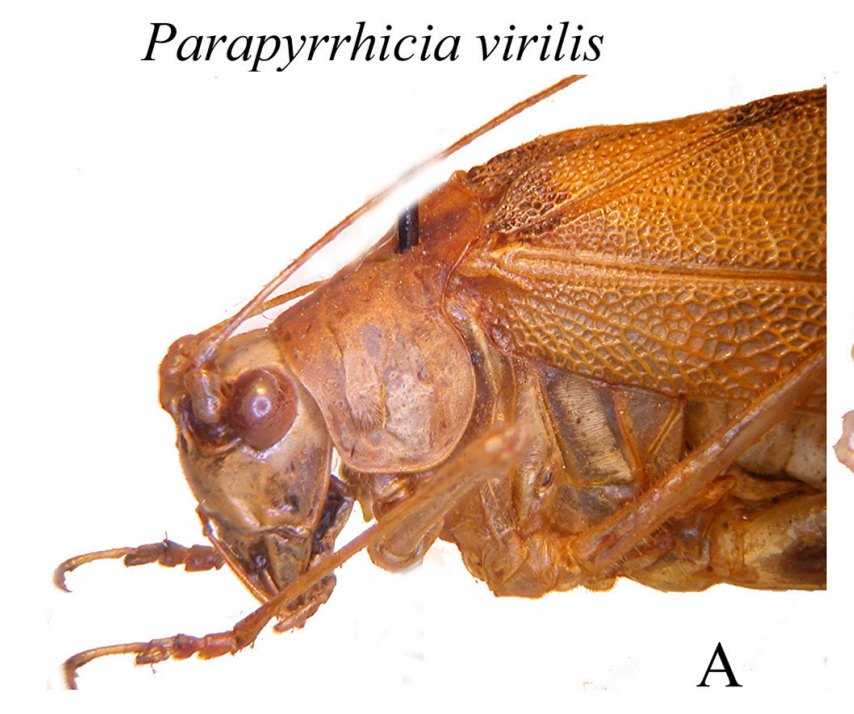

\section{Parapyrrhicia longipodex}
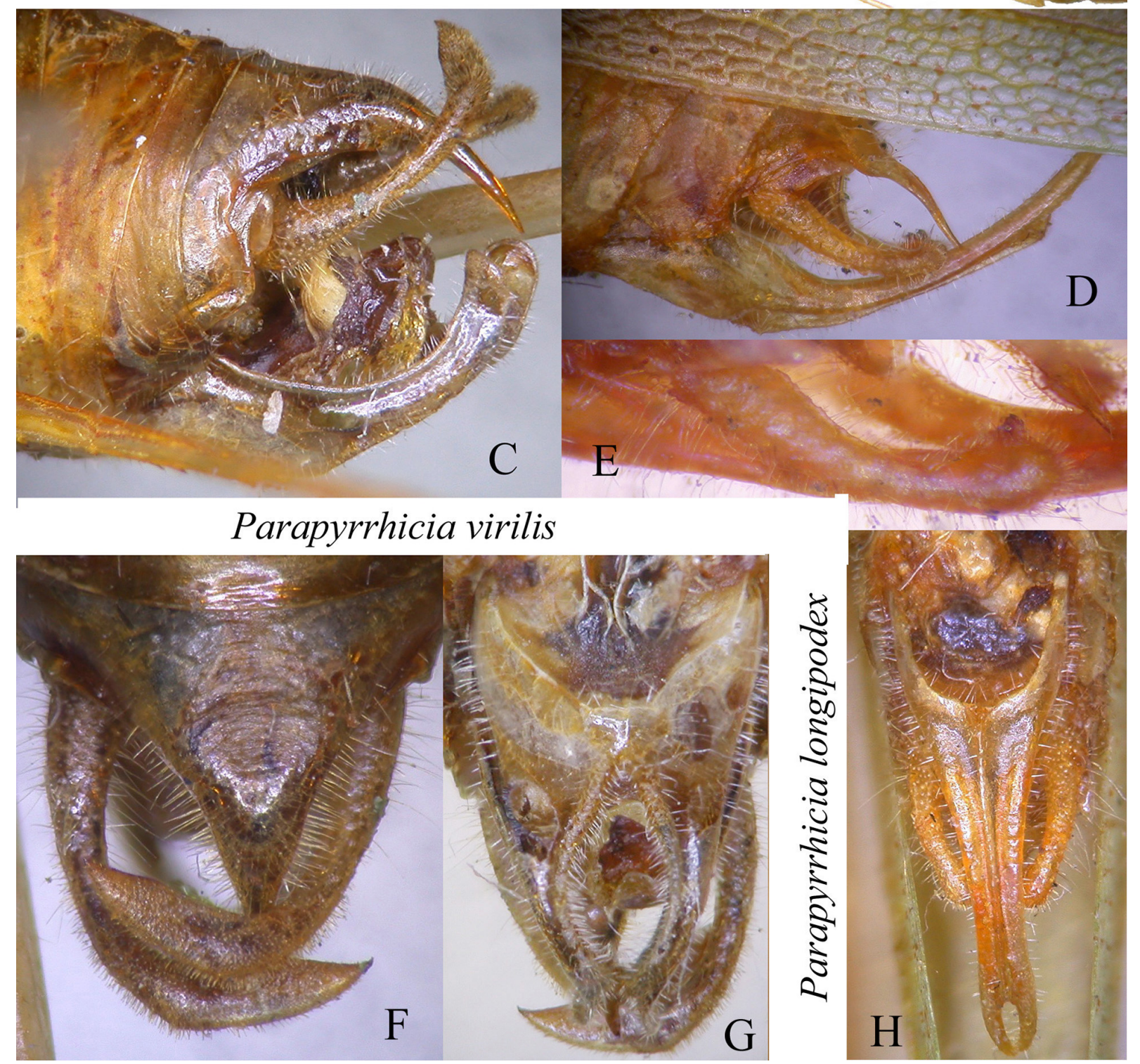

FIGURE 4. Parapyrrhicia virilis, male: lateral view of head and pronotum (A), lateral view of last abdominal segments (C), dorsal view of last tergite and cerci (F), subgenital plate (G); Parapyrrhicia longipodex n. sp., male: lateral view of head and pronotum (B), lateral view of last abdominal segments (D), cerci (E), subgenital plate (H). 
Female. Unknown.

Diagnosis. Parapyrrhicia longipodex is characterized by its long subgenital plate, last tergite and cerci. The absence of any black spot on the fore margin of tegmina and the different number of spines on hind femora allow to exclude that it may be the male of $P$. dentipes, of which only the female is known (black spots on the fore base of fore margin of tegmina, 10 outer and 3 inner ventral spines on hind femora: Saussure 1899). Differences from $P$. virilis may be noticed in the Fig. 4.

Etymology. From Latin: longipodex (= with long anus) refers to the long subgenital plate.

Measurements. Male. Body length: 20.0; length of pronotum: 4.2; height of pronotum 2.7; length of tegmina: 26.6; width of tegmina: 4.2; length of hind femora: 19.0 .

\section{Remarks on the genus Parapyrrhicia}

All the known species of Parapyrrhicia, present in Africa, Madagascar and in the Comores Is. are characterized by a more or less pronounced last sternite, that may be modified into two long lobes or may be more or less up-curved. However, some differences between Madagascar and African species may be noticed: 1) the ovipositor of African species (included also P. insularis of Comores Is.; cf. Chopard 1958) has denticulate apex (cf. Hemp et al. 2016), while that of Madagascar species has only serrate apex (at least in the two species $P$. virilis and $P$. dentipes, whose female is known); 2) the last tergite of Comore Is. and African species is generally unmodified (only in the African $P$. abdita is a little modified), while that of Madagascar species is modified, long and down-curved (at least in $P$. virilis and $P$. longipodex n. sp., whose male is known); 3) both females of African and Madagascar species have a stridulatory system on the veins of the right tegmen, but while Hemp et al. (2016) found them only on 2-3 transverse veins, in Madagascar P. virilis it was observed also in a longitudinal vein. The genus Parapyrrhicia certainly evolved in East Africa; Madagascar is isolated from Africa since ca. 65 millions of years (Briggs 2003), thus it is plausible that since that moment Madagascar Parapyrrhicia species lost their contact with African ones. Consequently P. abdita should be the sole African representative of the genus that presently has the character "last tergite modified". However, this might be considered only a case of convergence with Madagascar species having the same character. Concerning Comores Is., they are of volcanic origin and fauna and flora very probably immigrated from Africa to them. Thus, P. insularis from the Comores Is., that has not the last tergite modified, has the ovipositor denticulate and the subgenital plate ending with two long appendices (like some African species) is very probably belonging to the ancestral African group more than related to the Madagascar one.

\section{Madagascarantia new genus}

(Figs 5A-5D, 6G-6I)

Type species. Madagascarantia bartolozzii new species, here designated

Description. Large size, short head wide round eyes, fastigium of vertex sulcate, as large as scapus of antennae, separated from fastigium of frons and protruding a little above it (Figs 6G, 6H); face rather large (Fig. 6G). Pronotum just shorter than high, lateral carinae just evident, lateral lobes rounded, prozona hardly narrower than metazona (Fig. $6 \mathrm{H}$ ); anterior margin of pronotum hardly concave, posterior margin rounded, with evident lateral excisions. Tegmina much wider than pronotum length, 3.0 times longer than wide in the male, 2.5 times longer than wide in the female, leathery, with the apical margins obliquely cut; hind wings longer than tegmina (Figs 5A, 5B). Stridulatory area of the left tegmen just curved.

Fore coxae armed. Tympana on fore tibiae open on outer and inner sides. Ventral margins of fore and mid femora furrowed, fore femora with spines on ventral margins, ventral margins of hind femora with some spines. Fore tibiae superiorly flat, not furrowed, fore and mid tibiae with 1 spur on each side, hind tibia with 3 spurs on each side. Hind tibiae longer than femora. Accessory spine of lower margin of hind genicular lobe much reduced. Meso and metasternum rounded. Supra-anal plate of the male triangular and rounded. Cerci of the male stout, inand up-curved. Subgenital plate of the male long, rectangular, and apically just concave, styli very small. Ovipositor short, gently curved and toothed at the apex of ventral and dorsal valves, valves of similar length, apically rounded (Fig. 6I). Subgenital plate of the female short, triangular and apically pointed. 

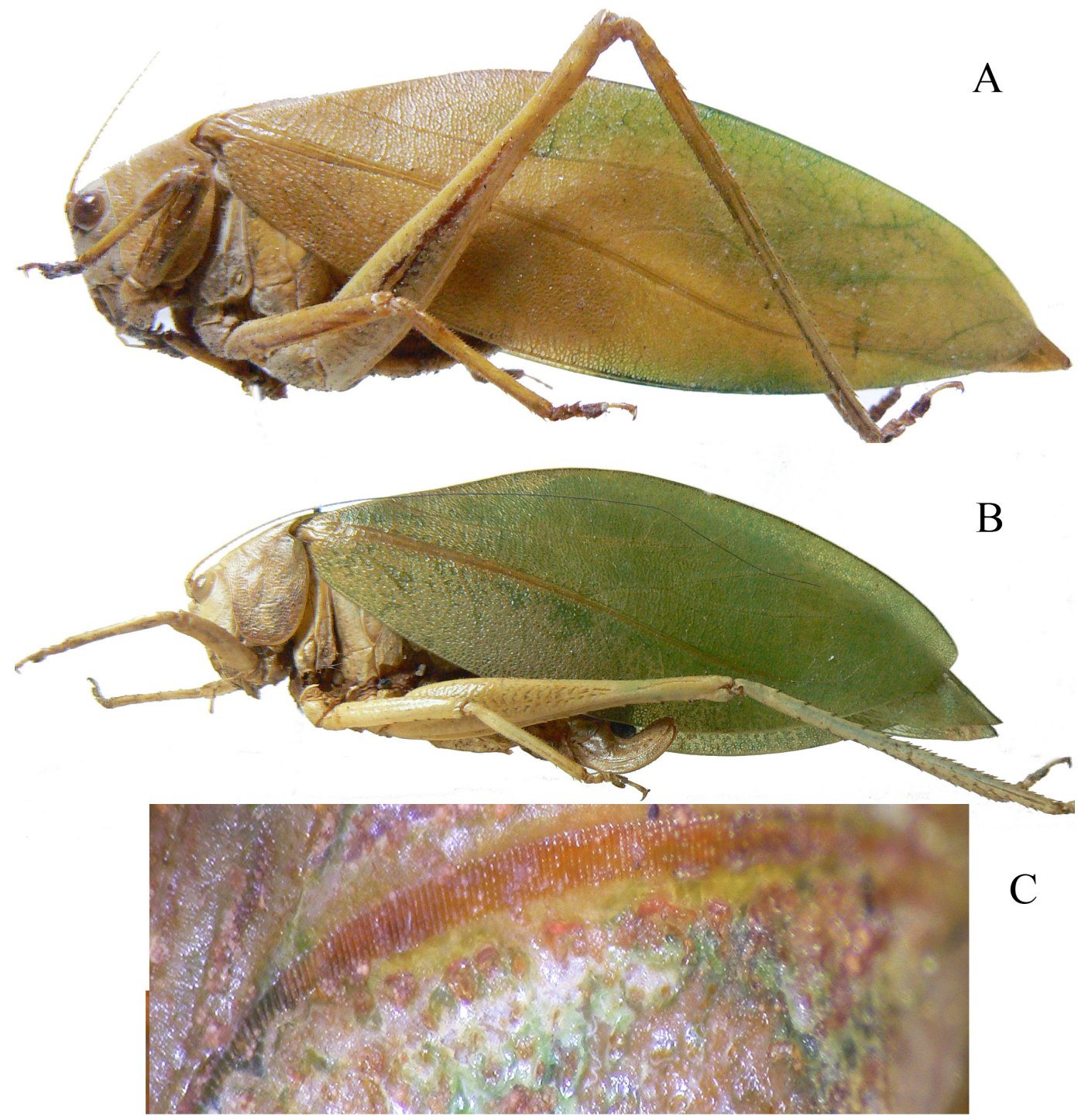

B

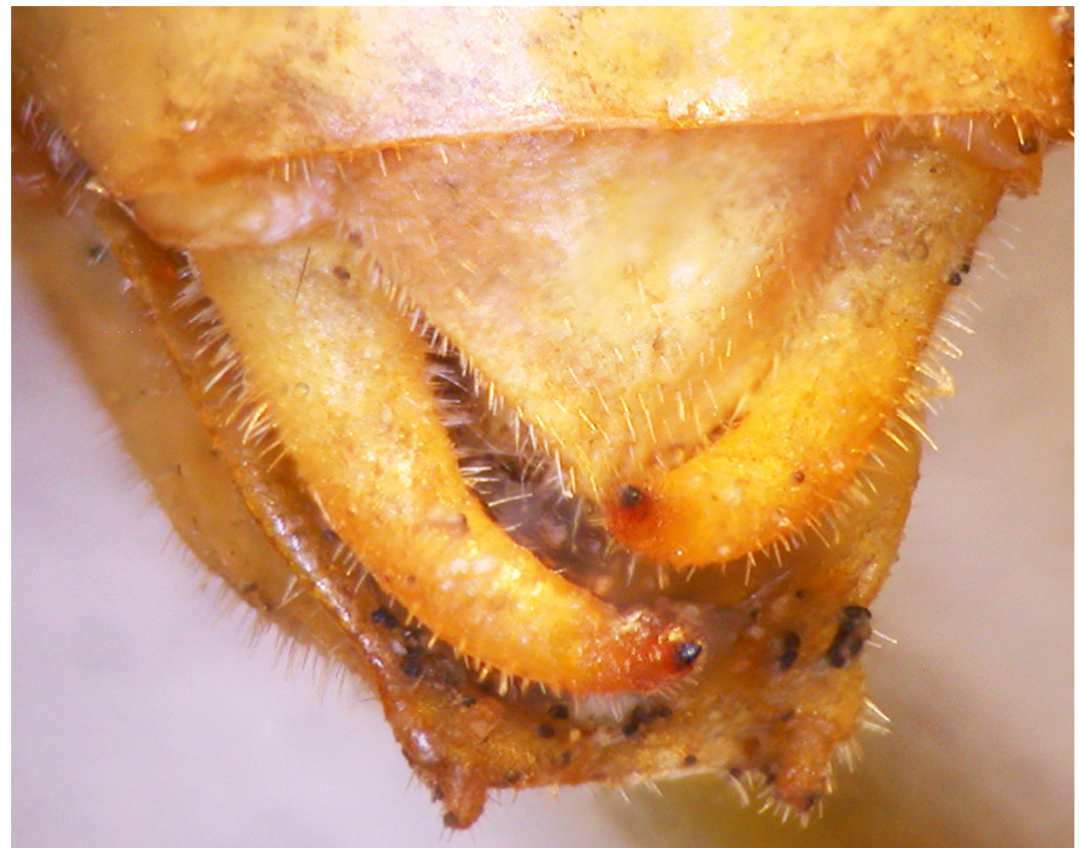

$\mathrm{C}$

D

FIGURE 5. Madagascarantia bartolozzii n. gen. n. sp., male (A) and female (B) habitus, male stridulatory file (C), dorsal view of last abdominal segments and cerci (D). 


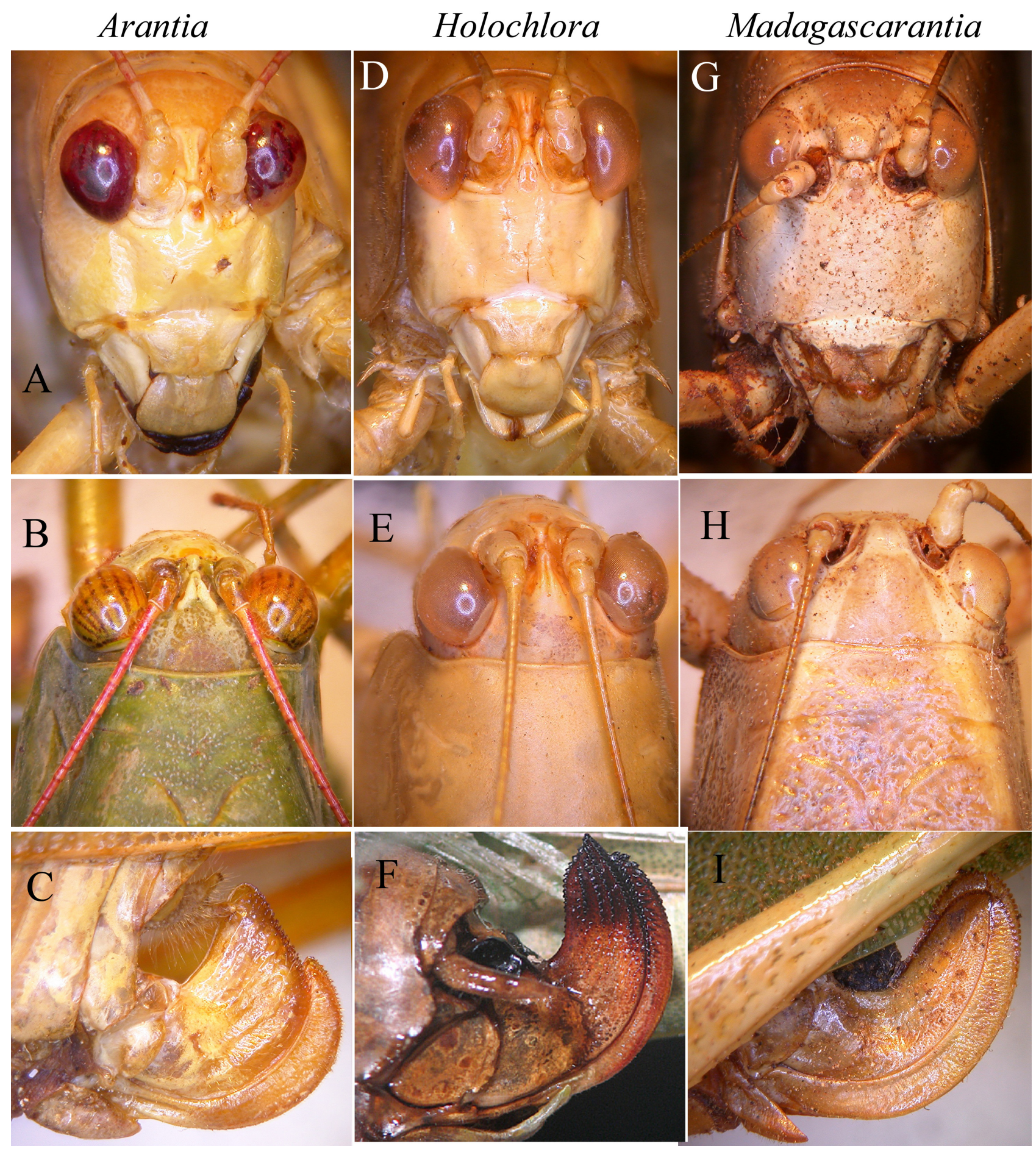

FIGURE 6. Arantia, Holochlora and Madagascarantia: face (A, D, G, respectively), fastigium of vertex and pronotum (B, E, $\mathrm{H}$, respectively), ovipositor (C, F, I, respectively).

Etymology. Suffix from the name of the isle of Madagascar, where it has been found attached to Arantia, vaguely similar, but probably not related genus.

Remarks. Madagascarantia n. gen. is vaguely similar to Holochlora Stål, 1873, Arantia Stål, 1874 (both subgenera Arantia and Euarantia Heller, 2014) and Goetia Karsch, 1891, from which may be separated by the differences listed in Table 1. See also Figs. 5A-5D, 6G-6I 
TABLE 1. Comparison of main morphological characters of Madagascarantia n. gen., Arantia Stål, 1874, Euarantia Heller, 2014 and Holochlora Stål, 1873.

\begin{tabular}{|c|c|c|c|c|}
\hline Character & Madagascarantia & Arantia/Euarantia & Goetia & Holochlora \\
\hline Fastigium of vertex & wider than scapus & as large as scapus & as large as scapus & as large as scapus \\
\hline Compound eyes & round & round & round & Semi-spherical \\
\hline Spine fore coxae & yes & no & yes & yes \\
\hline $\begin{array}{l}\text { Dorsal margin fore } \\
\text { tibiae }\end{array}$ & flat & furrowed & furrowed & furrowed \\
\hline Inner tympanum & open & closed & closed & closed \\
\hline Outer tympanum & open & open or closed & open & open \\
\hline $\begin{array}{l}\text { Stridulatory vein of left } \\
\text { tegmen }\end{array}$ & normal & normal & $\begin{array}{l}\text { normal or elevated } \\
\text { above wing plane }\end{array}$ & $\begin{array}{l}\text { elevated above wing } \\
\text { plane }\end{array}$ \\
\hline Stridulatory file & normal & normal & normal & bulging in middle \\
\hline Last tergite & not modified & not modified & not modified & modified \\
\hline Ovipositor & $\begin{array}{l}\text { robust, wide, apically } \\
\text { rounded }\end{array}$ & $\begin{array}{l}\text { small, reduced, valves of } \\
\text { different length }\end{array}$ & $\begin{array}{l}\text { small, reduced, valves } \\
\text { of different length }\end{array}$ & $\begin{array}{l}\text { robust, wide, apically } \\
\text { tipped }\end{array}$ \\
\hline
\end{tabular}

Differences do not allow to include Madagascarantia n. gen. within neither Holochlorini Brunner von Wattenwyl, 1878 nor Arantiini Brunner von Wattenwyl, 1878; in particular open tympana (Ragge 1980) suggest to consider it related to Symmetroraggea Massa, 2015 and tentatively to include it to the tribe Phaneropterini Burmeister, 1838; however, the dorsal margin of fore tibiae not furrowed, in common with Symmetroraggea, and Parapyrrhicia puts in doubt this choice.

\section{Madagascarantia bartolozzii new species}

(Figs 5A-5D, 6G-6I)

Material examined and depository. Holotype $\hat{\sigma}$, allotype $q$ and 1 paratype $\hat{\sigma}$. Madagascar, Sikora, N.M. Kheil (NMHP). Paratype $\delta^{\uparrow}$. Madagascar, Ambila Le Maintso V.1990, C. Raharimina (MZUF).

Measurements. Males. Body length: 27.5-28.2; pronotum length: 6.8-7.4; pronotum height: 6.9-7.0; hind femur: 19.5-20.0; hind tibiae: 21.9-23.5; tegmina: 43.2-43.8; length of hind wings: 46.4-46.6; tegmina width: 14.3-14.7. Female. Body length: 29.9; pronotum length: 7.8; pronotum height: 7.0; hind femur: 20.9; hind tibiae: 22.0; tegmina: 43.6 ; length of hind wings: 47.6 ; tegmina width: 17.2 .

Diagnosis. It is a large species, characterized by open tympana on inner side of fore tibiae, lateral lobes of pronotum wrinkled and stout in- and up-curved cerci.

Description. Male. General habitus and colour. Predominantly green, head and pronotum brown-yellowish, legs yellowish (Fig. 5A). Head and antennae. Eyes round, fastigium of vertex sulcate, as large as scapus of antennae, separated from fastigium of frons and protruding a little above it (Figs 6G, 6H). Head and legs yellow, face yellow. Thorax and legs. Pronotum green, just shorter than high, lateral lobes wrinkled, anterior margin hardly concave, posterior margin rounded (Fig. 6H), with evident lateral excisions, prozona hardly narrower than metazona, lower margin of pronotal lobes rounded. Tegmina oval, green, 3.0 times longer than wide. The stridulatory area of the left tegmen is just curved, the stridulatory file is arcuate, ca. $2.4 \mathrm{~mm}$ long, and consists of ca. 120 evenly spaced teeth (Fig. 5C).

Fore coxae armed with a fine spine. Tympana on fore tibiae open on outer and inner sides. Fore femora with 4 inner ventral spines, fore tibiae with 2-3 inner ventral spines, superiorly flat, not furrowed. Mid femora with 3-4 outer ventral spines, mid tibiae ventrally with 4 outer and 2-3 inner spines. Hind femora with 5-8 outer and 1-2 inner ventral spines, hind tibiae straight, longer than femora, with 12 outer and 10 inner ventral spines.

Abdomen. Cerci stout, in- and up-curved, with a small apical spine (Fig. 5D). Subgenital plate long, rectangular, and apically just concave, styli very small (Fig. 5D).

Female (Figs 5B, 6I). Same characters of the male, tegmina 2.5 times longer than wide, ovipositor short, gently 
curved and toothed at the apex of ventral and dorsal valves, valves of similar length, apically rounded (Fig. 6I). Subgenital plate short, triangular and apically pointed.

Etymology. This species is named after Luca Bartolozzi, distinguished entomologist, curator of insect collections of the Museo di Zoologia 'La Specola' of the Florence University.

Distribution. Actually Madagascarantia bartolozzii n. sp. seems to be a relict taxon, isolated only in Madagascar.

\section{Phaneropterinae of uncertain tribe}

\section{Gen. Mimoscudderia Carl, 1914}

The genus Mimoscudderia is characterized by fastigium of vertex narrow, furrowed, not contiguous with fastigium of frons, wide eyes (higher than large), pronotum rounded in metazona, little enlarged in prozona, tegmina rather narrow, all femora inferiorly armed, hind genicular lobes provided with two small spines, and styli absent. It is known only from Madagascar, where Carl (1914) described two species, one only on the female sex, the other on both sexes. The specimen listed below is tentatively placed within this genus (the eyes are round, not wide and elliptical, like in other Mimoscudderia); its characters allow to ascribe it to a new species.

\section{Minoscudderia spinicercata new species}

(Figs 7A-7G)

Material examined. Holotype $\widehat{\jmath}$. Madagascar, Vohémar (NHMP).

Description. Male (Figs 7A-7G). Colour. Yellowish, posterior margin of pronotum laterally black, anterior margin of tegmina black, followed by a white stripe along nearly all margin (Figs 7A, 7B). Fastigium of vertex narrow, furrowed above, clearly separated by fastigium of frons (Fig. 7C). Eyes round, well projecting, with frontogenal carinae below them. Legs comparatively long. Fore coxae armed with a well-developed spine. Fore tibiae furrowed superiorly, distinctly widening above tympanum, which is open on both sides. Fore femora armed with 8 inner ventral spines +1 spur, 7 outer ventral margin +1 spur, mid tibiae with 12 spines on outer ventral margin and unarmed inner ventral margin +1 spur on each side, hind femora armed with 9 spines on inner and outer margins, hind tibiae with many spines on ventral and dorsal margins +3 spurs on each side. Pronotum narrowing anteriorly, flat above, anterior margin straight, posterior margin widely rounded, humeral sinus evident, lobes of pronotum rounded and short (Fig. 7B). Tegmina comparatively narrow with rounded apices. Wings just long as tegmina. Stridulatory area of left tegmen narrow, stridulatory file curved and consisting of ca. 50 teeth evenly spaced (Fig. 7D). $10^{\text {th }}$ tergite with straight hind margin, cerci long, stout, incurved, a chitinous inner spine subapically placed (Figs 7E-7G). Subgenital plate short, trapezoidal, styli absent (Fig. 7G).

Diagnosis. This taxon is tentatively placed within the genus Mimoscudderia, differences from it lie mostly on the eye shape. Differences from the two known species M. modesta Carl, 1914 and M. picta Carl, 1914 are mostly on the colour of tegmina. It is also characterized by a subapical spine on the cerci and very short pronotum lobes.

Measurements. Male. Body length: 23.7; length of pronotum: 4.7; height of pronotum 4.5; length of tegmina: 34.2; width of tegmina: 6.8; length of hind femora: 17.6.

Etymology. The name spinicercata refers to the inner subapical spine on cerci.

\section{Acknowledgements}

This paper is dedicated to all the curators of museum collections, who spend their life to catalogue, preserve and study specimens collected in all the parts of the world, and allow taxonomists to carry out their researches on this important witness of biological diversity. This research received support from the Synthesys Project, which is financed by European Community Research Infrastructure Action under the FP7 "Capacities" Programme at the Museo Nacional de Ciencias Naturales, Madrid (CSIC) (2013: ES-TAF-2438), the Museum für Naturkunde, Berlin 


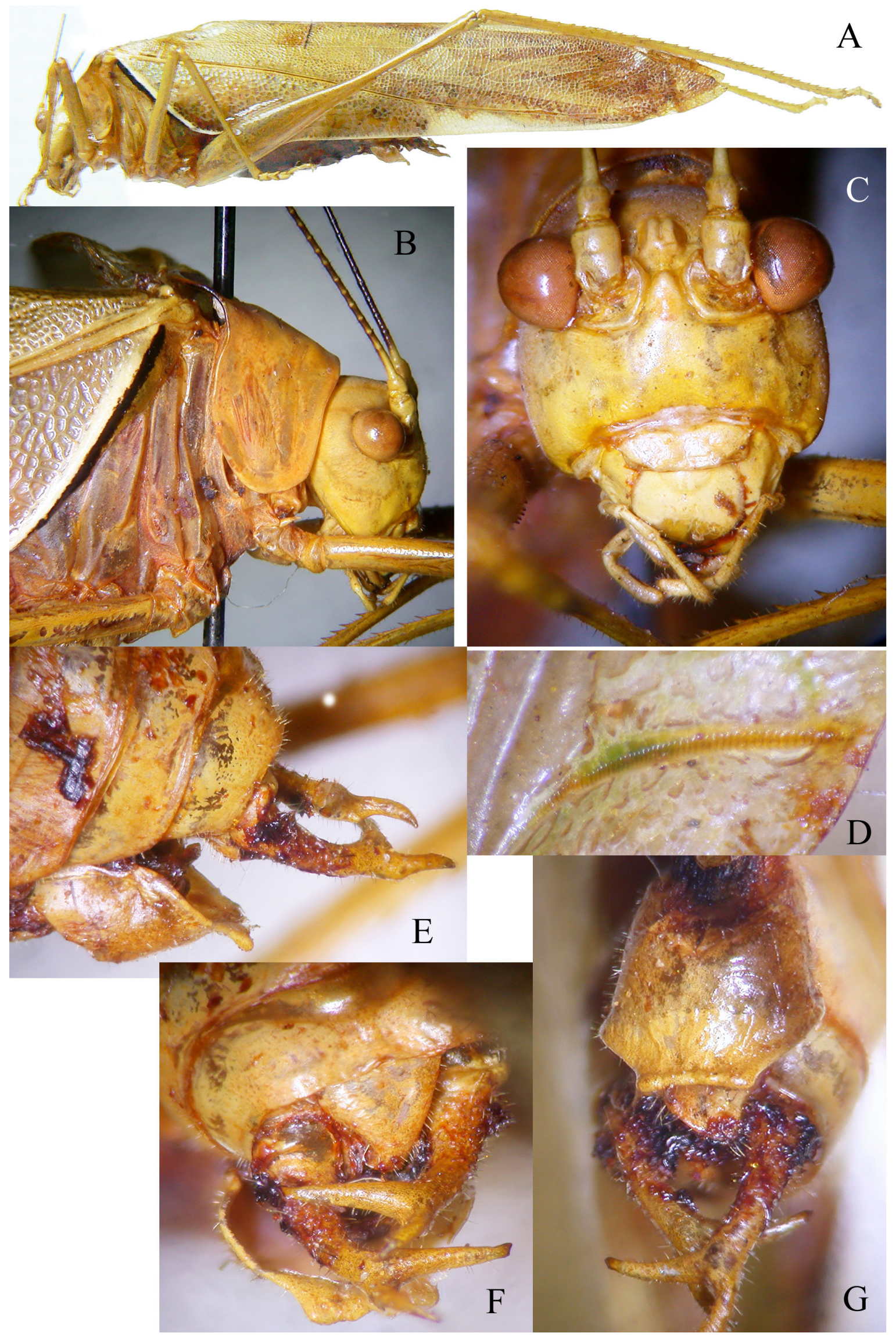

FIGURE 7. Mimoscudderia spinicercata n. sp., male: habitus (A), lateral view of head and pronotum (B), face (C), stridulatory file (D), lateral (E) and dorsal view (F) of last abdominal segments and cerci, subgenital plate (G). 
(2014: DE-TAF-4109), the Naturhistorisches Museum, Vienna (2016: AT-TAF-5324), and the National Museum of Natural History, Prague (2016: CZ-TAF-5559). I am especially indebted to Mercedes Paris (Museo Nacional de Ciencias Naturales of Madrid), Michael Ohl (Museum für Naturkunde of Berlin), Suzanne Randolf and Harald Bruckner (Naturhistorisches Museum, Vienna), Martin Fikáček (National Museum Natural History, Prague), Laure Desutter and Simon Poulain (Muséum National d'Histoire Naturelle, Paris), Roberto Poggi, Maria Luisa Tavano and Giuliano Doria (Museo Civico di Storia Naturale 'G. Doria' of Genoa), Luca Bartolozzi (Museo di Zoologia 'La Specola', University of Florence) who facilitated the study of specimens preserved in their museums.

\section{References}

Briggs, J.C. (2003) The biogeographic and tectonic history of India. Journal of Biogeography, 30, 381-388. https://doi.org/10.1046/j.1365-2699.2003.00809.x

Carl, J. (1914) Orthoptères de Madagascar (Phaneropterides et Pseudophyllides). Revue Suisse de Zoologie, 22 (6), 147-177. https://doi.org/10.5962/bhl.part.82532

Chopard, L. (1958) Les Orthopteroides des Comores. Mémoires de l'Institut Scientifique de Madagascar, Série E Entomologie, $10,3-40$.

Cigliano, M.M., Braun, H., Eades, D.C. \& Otte, D. (2016) Orthoptera Species File. Version 5.0/5.0. Avaliable from: http:// Orthoptera.SpeciesFile.org (Accessed 9 Mar. 2017)

Heller, K.-G., Hemp, C., Ingrisch, S. \& Liu, C. (2015) Acoustic Communication in Phaneropterinae (Tettigonioidea) - A Global Review with Some New Data. Journal of Orthoptera Research, 24, 7-18. https://doi.org/10.1665/034.024.0103

Hemp, C., Heller, K.-G., Warchalowska-Sliwa, E., Grzywacz, B. \& Hemp, A. (2016) Review of the East African species of the phaneropterine genus Parapyrrhicia Brunner von Wattenwyl, 1891 (Insecta: Orthoptera): Secret communication of a forest bound taxon. Organisms, Diversity \& Evolution, 1-20. [published online] https://doi.org/10.1007/s13127-016-0303-5

Massa, B. (2015) New genera, species and records of Phaneropterinae (Orthoptera, Phaneropteridae) from sub-Saharan Africa. Zookeys, 472, 77-102. https://doi.org/10.3897/zookeys.472.8575

Ragge, D.R. (1980) A review of the African Phaneropterinae with open tympana (Orthoptera: Tettigoniidae). Bulletin British Museum (Natural History) Entomology, 40, 1-192. Avaliable from: http://www.archive.org/details/bulletinofbritis40entolond (Accessed 9 Mar. 2017)

Saussure, H. de (1899) Orthoptera. Wissenschaftliche Ergebnisse der Reisen in Madagaskar und Ostafrika in den Jahren 188995 von Dr. A. Voeltzkow. Abhandlungen der Senckenbergischen Naturforschenden Gesellschaft, 21, 567-664. Avaliable from: http://www.biodiversitylibrary.org/item/85045\#page/613/mode/lup (Accessed 9 Mar. 2017) 